\title{
O corpo nos contextos do cuidado: reflexões sobre as concepções no campo da enfermagem
}

\author{
Bruna Motta dos Santos ${ }^{1}$ \\ Universidade Federal de Juiz de Fora
}

Resumo: O trabalho busca tecer algumas considerações e reflexões acerca de como o corpo é percebido no âmbito da Enfermagem, partindo da bibliografia da área sobre o tema. Através desse olhar sobre o ambiente nativo, percebeu-se que a área possui grande influência do modelo biomédico. Entretanto, as dimensões psicológica, social, emocional e cultural aparentam ter bastante relevância, principalmente quando a categoria estudada aparece junto à noção de cuidado, reivindicada como prática específica e essencial para a atuação da (o) enfermeira (o). Nesse sentido, parece-nos que o cuidado se constitui como uma forma de se distanciar do paradigma mecanicista e de suas consequências, trazendo consigo uma certa autonomia à atividade das enfermeiras e enfermeiros, como um fazer distinto da medicina em termos de despersonalização e atenção a integralidade do outro.

Palavras-chave: corpo; enfermagem; biomedicina; cuidado; integralidade. 


\title{
Body in career contexts: reflections on nursing field conceptions
}

\begin{abstract}
The work seeks to weave some considerations and reflections about how the body is perceived in the scope of Nursing, starting from the bibliography of the area on the theme. Through this look at the native environment, it was realized that the area has great influence from the biomedical model. However, the psychological, social, emotional and cultural dimensions appear to be quite relevant, especially when the category studied appears alongside the notion of care, claimed as a specific and essential practice for the nurse's performance. In this sense, it seems to us that care is constituted as a way to distance itself from the mechanistic paradigm and its consequences, bringing with it a certain autonomy to the activity of nurses, as a different activity from medicine in terms of depersonalization and attention to integrality of the other.
\end{abstract}

Keywords: body; nursing; biomedicine; care; completeness.

\section{Cuerpo en contextos de carrera: reflexiones sobre concepciones de campo de enfermería}

\begin{abstract}
Resumen: El trabajo busca tejer algunas consideraciones y reflexiones sobre cómo se percibe el cuerpo en el ámbito de la Enfermería, a partir de la bibliografía del área sobre el tema. A través de esta mirada al entorno nativo, se dio cuenta de que el área tiene una gran influencia del modelo biomédico. Sin embargo, las dimensiones psicológicas, sociales, emocionales y culturales parecen ser bastante relevantes, especialmente cuando la categoría estudiada aparece junto con la noción de cuidado, considerada como una práctica específica y esencial para el desempeño de la enfermera. En este sentido, nos parece que el cuidado se constituye como una forma de distanciarse del paradigma mecanicista y sus consecuencias, trayendo consigo una cierta autonomía a la actividad de las enfermeras, como una actividad diferente de la medicina en términos de despersonalización y atención a integralidad del otro.
\end{abstract}

Palabras clave: cuerpo; enfermería; biomedicina; cuidado; integridad. 
$\mathrm{T}$ Tratar de questões que envolvem o corpo implica que trilhemos um caminho contornado por fenômenos de natureza orgânica e social e a maneira de conceber e lidar com aspectos que o contornam, como os seus usos, os sentidos que lhe são atribuídos, suas práticas e formas, variam a depender do contexto considerado, o que nos mostra como o corpo se apresenta como um elemento apropriado, significado e modelado social e culturalmente. Como afirmou Le Breton (2012), a vivência humana, em termos físicos, está sujeita a um conjunto de sistemas simbólicos e a partir do corpo se originam e se difundem sentidos diversos que servem de base a existência coletiva, fazendo com que ele se constitua, "em primeiro lugar, [como] uma estrutura simbólica, superfície de projeção passível de unir as mais variadas formas culturais" (2012: 29).

Nesse sentido, tanto as ações do corpo consideradas em sua dimensão coletiva, quanto as formas e teorias para explicá-lo e concebê-lo são forjadas socialmente. O corpo está eivado por imaginários sociais que são parte das concepções de mundo, vinculadas ao estado social e à noção de pessoa de cada coletividade. Essas concepções, variáveis de sociedade para sociedade, revestem o corpo de sentido, lhe atribuem valor e situam seu lugar na estrutura simbólica de determinado grupo, designando seu funcionamento e suas partes, significando ações e expressões, localizando todos esses elementos em concordância com visões de mundo específicas (LE BRETON, 2013).

Tendo em vista estas considerações, o que nos interessa no presente trabalho é pensar o corpo nesta dimensão particular, ou seja, refletir acerca das representações que dele são construídas a partir de um contexto bastante específico: a Enfermagem, uma prática profissional que compõe o campo da saúde e que possui questões muito específicas no seu fazer. Pretendemos, mais particularmente, tratar da Enfermagem e de suas concepções de corpo a partir do seu lugar como campo profissional, ou seja, como uma das profissões da área da saúde que, como sabemos, possui uma concepção bastante específica acerca do corpo. Para tal empreendimento, efetuaremos uma problematização da questão que nos norteou, seguida de uma breve discussão bibliográfica de produções que versaram sobre o tema na área da Enfermagem e, por fim, buscaremos lançar reflexões sobre as questões expostas.

\section{Corpo e o contexto da saúde}

Nas sociedades ocidentais modernas, as concepções dominantes acerca do corpo foram forjadas a partir do saber biomédico, sobre o qual se edificou e se debruça a biomedicina. Este modelo engloba um conjunto de saberes, práticas e valores, símbolos que são compartilhados por aqueles que constituem esse grupo social específico e exercem a medicina científica moderna, cuja função de curar é socialmente legitimada. Assim, os profissionais da medicina constituem uma cultura particular, dotada de uma visão de mundo e uma perspectiva biomédica que tem como premissas básicas aspectos como o dualismo corpo-mente, a racionalidade científica e a centralidade em elementos físico-químicos (HELMAN, 
2009).

Esse saber, que possui em nossas sociedades um status oficial, tem o estudo preciso do corpo humano como fundamento de sua base epistemológica que, ao separar corpo e pessoa, opera um dualismo que sustenta seus procedimentos e descobertas (LE BRETON, 2013). Como afirmou Helman (2009: 114), citando Kleinman, a visão médica ocidental moderna considera que os elementos biológicos possuem uma maior relevância, sendo "mais básicos, reais, clinicamente significativas e interessantes que os aspectos psicológicos e socioculturais". Ao direcionar-se em busca de dados físico-químicos, a medicina torna-os "fatos reais" em razão da possibilidade destes serem observados e quantificados, de modo "que um médico confrontado com os sintomas de um paciente tenta, antes de tudo, relacioná-los a algum processo físico subjacente (HELMAN, 2009: 114).

No intento de compreender a doença, a biomedicina a despersonaliza, situando-a como um defeito ou falha, "colocada como uma intrusa, nascida de uma série de causalidades mecânicas" (LE BRETON, 2013: 286). Segundo o modelo biomédico, o corpo passa a ser percebido, então, como uma composição de partes que juntas funcionam como uma máquina e, enquanto máquina, pode ser tomado com um objeto de controle humano. Com o corpo separado da pessoa e a possibilidade de enxergá-lo enquanto objeto para tratá-lo, o âmbito médico centra-se na máquina-humana e no que está interferindo em seu pleno funcionamento; a pessoa doente, sua história e singularidade, passam a ter importância secundária. A biomedicina, pautada na objetividade do saber e no fazer técnico, ocasiona uma cisão entre o doente e a doença, sendo o sujeito um corpo que necessita de reparos (LE BRETON, 2013).

Embora o saber biomédico desfrute de hegemonia e legitimidade, ele se constitui como um dos muitos saberes e práticas acerca do corpo, dada a heterogeneidade de sentidos e imaginários a ele atribuídos, de maneira que "nenhuma representação do corpo faz unanimidade, nem mesmo o modelo anatomofisiológico" (LE BRETON, 2012: 29), mesmo que este se mantenha predominante. Le Breton (2013) explica que, em uma sociedade em que o individualismo se faz presente em sua estrutura, a vida coletiva ganha uma pluralidade e polifonia no que se refere a seus referenciais, movimento que atinge também as representações do que é o corpo. Entretanto, mesmo no âmbito da saúde, local de emergência dessa representação hegemônica e composto por práticas heterogêneas, diversas representações de corpo coexistem paralelamente à representação biomédica.

A Enfermagem é uma profissão pertencente ao âmbito da saúde que se define pelo cuidado e situa-o como essência da profissão, uma prática que compreende um conjunto de conhecimentos e atividades técnicas entendido como específico da atuação das enfermeiras e enfermeiros. Abordado como integral e holístico, o cuidado em enfermagem procuraria não reduzir e fragmentar o paciente e centrar nele a assistência, considerando-o enquanto uma unidade (NETO e NÓBREGA, 1999). Como afirmaram Dias et al. (2014: 1338) "no âmbito da Enfermagem, para que haja cuidado, o profissional deve extrapolar suas habilidades técnicas, que são indispensáveis nesse processo, e centrar o paciente como núcleo desse processo".

Embora a Enfermagem se constitua como um ofício que necessita de uma formação acadêmica para ser exercido - formação esta pautada em diretrizes técnico-científicas segundo o modelo biomédico -, ela é uma profissão que se coloca desafios e questões diferentes, propondo uma prática específica no seu fazer. Isso levou-nos a pensar acerca das representações na área da saúde, mais especifica- 
mente das que se referem ao corpo, na qual o caráter oficial é dado pela biomedicina. Dito de outro modo, nosso objetivo no presente trabalho é pensar as concepções de corpo da área da Enfermagem em um terreno em que a legitimidade é dada pela área médica.

\section{Corpo: qual a concepção das enfermeiras e enfermeiros?}

O corpo e as questões a ele relacionadas parecem ser um foco de atenção e preocupação na literatura em Enfermagem, dado o número de trabalhos que dele buscaram tratar sob as mais diversas abordagens. As referências que se seguem são trabalhos da área da enfermagem que buscaram tratar da concepção de corpo e, de certo modo, se constituem em discursos nativos sobre o tema, já que tratam do campo do qual fazem parte, ou seja, enfermeiros falando sobre enfermeiros. $\mathrm{O}$ que pretendemos, portanto, é pensar a concepção nativa de corpo a partir do que foi produzido na área, no intento de trazer algumas reflexões sobre como enfermeiras e enfermeiros entendem a categoria.

Ao pensar como o corpo é percebido no contexto da enfermagem, com a finalidade de possibilitar uma nova concepção do cuidar, Polak (1996) elenca três categorias: o corpo ritualizado, o corpo mecanizado e o corpo sexuado. A primeira dessas dimensões discutida pela autora é a dimensão ritualizada do corpo, que estaria presente na totalidade da hospitalização, como nos momentos de recuperação, fase terminal ou nascimento do sujeito, etapas marcadas por transformações e que se constituem em ritos de transição social ou ritos de passagem. Estas etapas dizem respeito à totalidade da vivência durante os processos de cura, momentos estes que abarcam o contexto interno e externo ao hospital e que contam, em todo o seu decorrer, com a presença do profissional da enfermagem.

Tais ritos possibilitam a definição de papéis, a expressão das condições de saúde ou de
doença, presentes no contexto hospitalar, bem como a expressão de todo o significado
e simbolismo presentes nas práticas de enfermagem, desenvolvidas nesse contexto,
seja no procedimento de admissão do cliente na instituição hospitalar, seja durante o
processo de cuidar e de curar, seja no procedimento de saída do cliente da instituição,
em caso de alta hospitalar; seja na ajuda do cliente no processo de morrer ou, após a
morte, durante o preparo do corpo. (POLAK, 1996: 69)

As ações do profissional da enfermagem frente às condições do sujeito são já estabelecidas, prescritas; atividades institucionalizadas e dotadas de valores. Para Polak, informar ao sujeito as condições de sua enfermidade e a comunicação de sua situação aos familiares são ações que também possuem caráter ritualístico. Diversos aspectos integram o ritual, envolvendo normas e padrões em sua utilização e execução, como "o uniforme, a expressão facial, a habilidade motora no manejo do instrumental, bem como a higienização das mãos, antes e depois do curativo, combinam com o silêncio, com as falas e as pausas" (POLAK, 1996: 67).

Polak (1996: 71-72) aponta, também, como o corpo é percebido de forma mecanizada ou, em outras palavras, enquanto uma máquina "formada por carne e ossos, composta por válvulas e sifões, por membranas e filtros”, consistindo a doença em um mecanismo biológico que interfere no seu funcionamento e a saúde como a ausência das patologias. A autora pontua a influência dessa perspectiva no âmbito da Enfermagem, já que esse pensamento fundamenta a medicina moderna, cuja visão se constituiu como dominante no campo da saúde. Dessa forma, o tratamento do sujeito caracteriza-se pelo estranhamento, muitas vezes desconsiderando aquele que recebe as ações do profissional, que tem suas atividades 
permeadas pela impessoalidade. A saúde e a doença acabam, assim, sendo separadas da dimensão subjetiva, de maneira que os corpos dos sujeitos "nos leitos das enfermarias, sentados nas salas de espera, são quase sempre vistos na terceira pessoa" (POLAK, 1996: 74). Apoiados nesta noção, o olhar da equipe volta-se à "parte" doente, ao órgão e não à totalidade do sujeito, que se torna um instrumento de trabalho. Por essa razão, a concepção de corpo mecanizado, de acordo com Polak, estaria também associada ao corpo percebido enquanto utensílio ou objeto, utilizado como instrumento de intervenção e a serviço de outrem.

O corpo sexuado, terceira categoria elencada pela autora, está associado à predominância da mulher no âmbito da enfermagem. Segundo Polak (1996), as profissões são sexuadas e no caso da Enfermagem, o ofício está associado ao cuidado prestado pelas mulheres ao longo da história, como os partos e os processos de cura ou, ainda, pela imagem feminina associada à noção de procriação e criação dos filhos. Esse aspecto gera uma série de implicações à profissão, como a submissão da enfermeira à figura do médico, questões relacionadas à remuneração e à valorização do trabalho e a relação de gênero no momento da interação entre o cuidador e o cuidado.

\footnotetext{
Pelos seus corpos elas concebem a vida, mantêm-se em contato com a natureza, cuidam de recém natos, ajudam-nos a se tomarem adultos e assistem-nos no processo de morrer. A enfermeira e a mulher assumem o papel de sacerdotisas nos rituais de passagem da vida para a morte. (POLAK, 1996: 86)
}

Fernandes e Lopes (2000), ao buscarem compreender quais eram as representações de corpo, saúde e doença destes profissionais, chegaram a três categorias que dizem respeito à forma como os profissionais o concebem. A primeira é o corpo anatômico, categoria presente em diversos trabalhos e que, na referida investigação, foram percebidas a partir da definição do corpo através de termos como tronco, cabeça, mãos e pernas. Neste caso, o foco seria o corpo enquanto uma entidade física constituída por diversas partes, sendo que "o conceito para esse grupo de enfermeiros reflete uma matriz de objetividade mecânica" (FERNANDES e LOPES, 2000: 7). O segundo eixo apontado pelas autoras consistiria no corpo enquanto instrumento de ação, que concerne ao corpo considerado enquanto estrutura que funciona, que se movimenta, que possui ação, sentimento e emoção, que "expressa trabalho, saúde, movimento e vida". O terceiro e último eixo de representação a que chegaram as autoras foi o corpo discursivo, que consiste no corpo em sua dimensão comunicativa, que fala, que diz algo "com os olhos, mãos, com as mãos com a cabeça, com todo o corpo" (FERNANDES e LOPES, 2000: 7), que vai dizer quem somos, nos categorizando e diferenciando socialmente.

Lima e Brêtas (2006) buscaram compreender como estudantes de enfermagem, graduandos de diversos períodos, percebem e representam os corpos cuidados, alcançando quatro categorias que dizem respeito à percepção e representação do corpo nesse contexto: o corpo objeto de cuidado, corpo objeto de estudo, corpo enquanto objeto de exercício de poder e, por fim, o corpo estigmatizado. A representação do corpo como objeto de cuidado, construído no processo de cuidar, o concebe sob a noção de inter-relação com o paciente, ou mais precisamente, em uma relação de intersubjetividade. O corpo, nesta perspectiva, é visto em sua totalidade, pois os estudantes "representam seu cliente como um corpo holístico" (LIMA e BRÊTAS, 2006: 728), sendo composto de uma esfera biológica, psicológica e social, tendo em vista a dimensão emocional, a biografia e a cultura daquele que é cuidado. 
Ao representar o cliente como um corpo biopsicossocial, as estudantes citaram a doença como uma causa de desequilíbrio psicológico, e o toque como instrumento de cuidado, proporcionando um bem-estar ao outro e diminuindo sua dor. (LIMA e BRÊTAS, 2006: 728)

Já a representação do corpo como objeto de estudo é explicada em razão do sujeito cuidado se tornar parte do aprendizado dos estudantes de enfermagem no hospital-escola, uma representação que situa "o corpo do cliente como um 'boneco', um objeto servindo de estudo e "cobaia" para realizar os primeiros procedimentos" (LIMA e BRÊTAS, 2006: 728).

O corpo enquanto objeto de exercício de poder é representado pelos estudantes na forma como os sujeitos lidam com a sua presença no interior do hospital, enxergando-o como um corpo sem autonomia, instrumento de trabalho de quem detém o conhecimento institucionalizado para tal atividade. Aqui, a vestimenta do profissional também é mencionada como um elemento que carrega forte significado, associando-o ao seu papel na sociedade, aquele que detém o conhecimento técnico-científico, simbolizando "o poder para hospitalizar os pacientes, prescrever medicamentos e exames, orientação para o cuidado e alívio do sofrimento e detentor de conceitos científicos e técnico" (LIMA e BRÊTAS, 2006: 729). A estigmatização, por fim, é abordada pelos autores para caracterizar a rotulação oriunda de aspectos pessoais do sujeito cuidado, ou seja, o corpo estigmatizado é o corpo rotulado, de maneira que o sujeito recebe determinada característica pela forma como lida com a doença ou com o profissional.

\section{Alguns apontamentos}

As concepções de corpo de enfermeiras e enfermeiros estão intimamente vinculadas às noções de saúde e de doença (OLIVEIRA, 1998), dado o caráter da atividade destes profissionais, que lidam com os cuidados sobre um corpo em condições de patologia ou de saúde. Segundo Fernandes e Lopes (2000), o corpo seria uma tela pela qual se expressam tais fenômenos, pois,

\footnotetext{
quando um corpo está com saúde exibe-a apresenta sentimentos de bem-estar, olhos brilhantes, pele rosada, bem-estar individual e social. Está em equilíbrio, está funcional. Quando o corpo está com doença denuncia-a; rebela-se contra as violências, os excessos, as frustrações, os ressentimentos, as covardias. O corpo doente é um corpo disfuncional, é um corpo em desequilíbrio. (FERNANDES e LOPES, 2002: 15)
}

Tanto os sintomas ou sensações corporais, quanto as interpretações a elas atribuídas, são efetuadas de acordo com códigos particulares pertencentes aos diferentes grupos, tanto leigos quanto profissionais, imagens que estão sujeitas às representações dominantes acerca da saúde e da doença em cada um desses agrupamentos, fazendo do corpo "um suporte de signos, ou seja, suporte de qualquer fenômeno gerador de significação e sentido" (FERREIRA, 1994: 102). O corpo enquanto signo, percebido como recinto da doença, passa a se constituir em um depositário de distintas interpretações, passíveis de leitura tanto por parte do profissional da saúde quanto pelo sujeito doente. Para o paciente, este processo de significação se direciona à dimensão dos sintomas, transmitidos ao profissional e, assim, culturalizados; já para o profissional da saúde, esse mesmo processo se evidencia nos sinais que são buscados nos exames físicos, na manifestação objetiva da doença, que a torna um fenômeno visível (FOUCAULT apud FERREIRA, 1994).

A partir das referências tratadas, é possível notar que uma das concepções acerca do corpo que mais se fazem predominantes na área da Enfermagem é a do 
corpo mecanizado ou anatomizado. Estas concepções se manifestam através de referências às noções de máquina, funcionamento e mecanismo e tratam o corpo a partir de uma fisicalidade cuja percepção e intervenção ocorrem tendo em vista as suas partes, separadamente, fenômeno que pode ser explicado pela influência da biomedicina sobre esta área.

Nos contextos da sociedade ocidental moderna, a biologia alcançou grande destaque na explicação dos processos de saúde-doença, o que tornou a biomedicina o modelo predominante no entendimento e tratamento das patologias. Como explicou-nos Bonet (2004), a aprendizagem da biomedicina ocorre através de uma profunda vinculação entre este modelo e o âmbito científico, que nos séculos XVI e XVII foi responsável por uma nova maneira de compreensão do mundo a partir de explicações metódicas e racionalistas. Como aponta o autor, tal racionalidade científico-mecanicista, nuclear no desenvolvimento da biomedicina, ocasiona não só uma separação entre a arte de curar e a disciplina das doenças, como produz um sistema classificatório das patologias, em um contexto em que os estudos de anatomia e fisiologia se davam nos moldes do mecanicismo. Ao lidar com corpos que possuem enfermidades, a área da saúde tem o ambiente hospitalar como principal estrutura científica que, possuindo uma cultura particular, tem em seus membros a legitimidade do saber e saber-fazer acerca das doenças, que se configuram enquanto "exigência da sociedade que não deseja cuidar, manipular secreções, conviver com odores e dores nos corpos dos seus familiares" (POLAK, 1996: 7).

A Enfermagem, por sua vez, foi uma profissão amplamente impactada pelo processo de institucionalização dos hospitais, momento em que estes deixam de ser um depositário de moribundos para se tornarem locais de cura (RIZZOTTO, 1995). No contexto hospitalar, a legitimidade e o poder de curar estavam depositados sobre a área médica, considerada como verdadeira detentora desse saber, fazendo com que outras profissões se situassem enquanto auxiliares nesse processo, incluindo a área da Enfermagem. Em seu estudo sobre a origem da Enfermagem profissional no Brasil, Rizzoto (1995) explica que dificilmente esta área percorreria um caminho distinto daquele trilhado pela Medicina, sendo a Enfermagem brasileira, desde os seus primórdios, fundamentada nos princípios do modelo biomédico e, por conseguinte, associada à medicina hospitalar. O mecanicismo, a ênfase nas investigações biológicas, a especialização, entre outros princípios, passaria a orientar também as práticas realizadas pela Enfermagem, importadas do modelo das escolas norte-americanas trazido para a formação brasileira.

Nesta acepção, também é possível dar inteligibilidade ao corpo visto como sexuado já que, dentro da divisão social do trabalho dentro do hospital, além da separação das funções de curar e de cuidar, estavam presentes as questões de gênero, sendo a Enfermagem, até os dias atuais, um ofício predominantemente feminino. Para Silveira, Gualda e Sobral (2003), a relação estabelecida entre corpo e Enfermagem é delicada. Traçando uma perspectiva histórica da profissão, as autoras apontam como a Enfermagem moderna teria se constituído sob o modelo cartesiano-biomédico e influenciada, em seus primórdios, pela visão cristã, campos responsáveis por lhe conferir concepções dualistas como mente-corpo e sagrado-profano. Na obra Notas sobre a Enfermagem (1859), Florence Nigthingale (1820-1910), apontada pela história da profissão como a figura central para o seu processo de institucionalização, situou o corpo como depositário da mente, ali colocada por Deus, apontando a importância das leis divinas para a relação entre 
o corpo e o mundo e as influências mútuas estabelecidas entre a dimensão corpórea e a mente. Nesse sentido, para se estabelecer enquanto prática profissional institucionalizada e reconhecida, a Enfermagem tinha o corpo como objeto de controle, principalmente no que tange à dimensão erótica, que deveria ser contida por meio de medidas direcionadas à conduta, vestimenta e até mesmo às emoções daquelas que se propunham à esta prática profissional (SILVEIRA, GUALDA e SOBRAL, 2003).

A reforma da Enfermagem, empreendida por Florence a partir de 1860, esteve, assim, embebida pela moralidade e o puritanismo, valores cultivados pela Inglaterra vitoriana. Sua preocupação era despertar a atenção de "moças de boa família" para esta prática, priorizando as qualidades morais das estudantes, num esforço para mudar um imaginário então em voga em relação à Enfermagem através da formação profissional (FONSECA et al., 2011). Esses elementos nos fazem lembrar a obra de Rohden (2009) que trata sobre a insistente diferenciação entre homens e mulheres operada pela biomedicina, aspecto este intimamente relacionado ao desenvolvimento da ciência, ao contexto da época - século XIX - e a questões vinculadas à dicotomia natureza e cultura. A autora mostra como a ciência, nesse sentido, passa a argumentar em favor de uma diferenciação biológica entre homens e mulheres e, por conseguinte, a necessidade de que essas diferenciações se estendessem à dimensão social, sendo a mulher objeto de controle. Entre essas ciências, a biomedicina tinha um papel particular, mobilizando argumentos que tornavam tal diferença indiscutível. Nas palavras da autora, "o modelo, para o qual os médicos davam consistência, servia como signo de uma ordem social marcada por diferenças de gênero" (ROHDEN, 2009: 31). Desse modo, parece-nos difícil não associar estes aspectos aos que envolvem a submissão da enfermeira ao médico, o controle de suas condutas ou até mesmo a divisão entre curar e cuidar, sendo este cuidado visto, muitas vezes, como a extensão de uma característica inata da mulher.

A profissionalização da Enfermagem se fundamentou, assim, no modelo biomédico. As (os) enfermeiras (os), conhecem o corpo cuidado por meio de uma representação anatomizada e pela patologia que o afeta, em um contexto cujo movimento tende para a especialização, tornando as relações cada vez mais impessoalizadas. Ainda em seu processo de institucionalização, Florence Nightingale reconheceu que, para cuidar de uma pessoa doente, era necessário possuir conhecimentos e habilidades que só poderiam ser alcançados através de um treinamento. (OGUISSO, 2007). Na sua concepção, com o intuito de auxiliar o paciente a viver, a Enfermagem deveria consistir em uma arte cujo treinamento e habilidade deveriam se pautar no científico, capacitando a enfermeira a servir à Medicina, à higiene e à cirurgia. Nesse sentido, ainda que os médicos - assim como o grande público - acreditassem ser desnecessária uma formação específica para enfermeiras, o prestigio de Florence fez com que eles assumissem o ensino teórico, pautados nos conteúdos de anatomia, fisiologia e farmacologia (OGUISSO, 2007), fazendo com que o modelo biomédico, em todas as suas práticas e concepções, não só impactasse o campo da Enfermagem, mas se tornasse parte constituinte do seu estabelecimento enquanto ciência.

Entretanto, quando nos voltamos à literatura da área, nos deparamos com a noção de cuidado, fundamental para entendermos a especificidade desta prática profissional. Desde o início de seu processo de institucionalização, que data o século XIX, a Enfermagem se estabeleceu como profissão norteada pelo cuidar, dispensando-o a sujeitos em contextos de saúde e doença. Em diversos trabalhos, ela é apontada como a arte e a ciência do cuidado, sendo o seu fazer uma junção 
entre estas duas dimensões. Nas palavras de Waldow (2012: 15), o cuidado é a "razão existencial da Enfermagem", tornando-o uma categoria amplamente mobilizada por estes profissionais para definirem seu ofício. Segundo Souza et al. (2005), o cuidado em Enfermagem é considerado para além de suas atividades técnicas e operacionais, sendo percebido como uma prática que se estende, também, a esfera subjetiva. É um cuidado abordado como integral e holístico, cuja percepção do sujeito deve ocorrer em sua dimensão biológica, almejando, porém, não perder de vista os aspectos sociais, psicológicos, emocionais e espirituais, buscando enxergar o sujeito em sua totalidade. Por meio dessa perspectiva, o cuidado em enfermagem anseia não reduzir e fragmentar o paciente e centrar nele a assistência, considerando-o enquanto uma unidade (NETO e NÓBREGA, 1999).

\begin{abstract}
O cuidar humanizado torna-se indispensável ao enfermeiro, que deve ir além do estudo de caso e tratar o paciente não como um mero objeto do processo de cuidar, visto que, como profissional, precisa transcender o cuidado propriamente dito, apresentar a capacidade de compreensão de quem é esse paciente, o que o levou ter a doença. A implementação das ações do cuidado no dia-a-dia do enfermeiro implica, também, perceber o paciente como um ser total, respeitar seus valores, crenças, sentimentos, emoções, e não apenas considerar o aspecto biológico. (BALDUINO, MANTOVANI e LACERDA, 2009: 344)
\end{abstract}

Nesse sentido, o tempo é um elemento importante para se compreender o cuidado, já que a prática da Enfermagem possui, como um dos elementos característicos e distintivos, a presença contínua junto ao outro, uma permanência que torna possível a proximidade e, consequentemente, o aspecto relacional presente na profissão (RENAUD, 2010). Esta dimensão relacional e de alteridade é intrínseca às relações que envolvem o cuidado, por consistir em um conjunto de gestos, palavras e valores que visam o auxílio e o acompanhamento de sujeitos em situações de fragilidade ou limitação, produzindo interações e colocando em questão a relação com o outro (SAILLANT e GAGNON, 1999). Dado o caráter temporal do cuidado, o profissional da Enfermagem mantém, com aquele que carece da assistência, uma relação de proximidade que não predomina em outras áreas da saúde, como entre os médicos que, priorizando aspectos técnicos, restringem a dimensão relacional às consultas ou visitas aos leitos que tem como finalidade o diagnóstico do paciente (LE BRETON, 2013).

Quando pensamos na especificidade do corpo nos contextos de cuidado, evidenciamos que ele não se constitui apenas como um objeto desse cuidado, o corpo é, também, percebido como o seu mediador. Para Fernandes (2016), os corpos dos pacientes e, sobretudo, os corpos dos profissionais da Enfermagem se apresentam como mediadores ao serem, ambos, permeados por histórias e memórias, sendo o cuidado o resultado desta inter-relação estabelecida entre os corpos cuidadores e cuidados. Já para Renauld (2010), o cuidado em Enfermagem é mediação que além de implicar uma dimensão objetiva, pautada na aprendizagem do saber acerca de sua execução, traz em si uma mediação que demanda o encontro daquele a quem se presta o cuidado e aquele que o fornece, envolvendo a exigência da presença corpórea, o que possibilita que o profissional alcance à integralidade do cuidado.

Este cuidado não é exclusivamente objetivo, não se limita a fornecer prestações de cuidado ao corpo. Ele é o cuidado de toda a pessoa, de tal modo que se exerce nele, uma resposta à pessoa doente encarada na complexidade do seu ser. Ainda que inclua uma dimensão de saber incidindo na prestação objetiva de um cuidado de que se pode aprender a execução, nos respectivos manuais, o cuidado de enfermagem atinge o nível de mediação em que se situa o corpo doente, ou o corpo carente de cuidados (como nos cuidados preventivos). Mas a pessoa da enfermeira ou do enfermeiro vive também nela ou nele esta dimensão de mediação, que surge entre a sua vida interior e a sua abertura 
ao mundo. É, portanto, um encontro de mediações, que surge entre o doente e a pessoa prestadora de cuidados, mediações que implicam sempre a presença assaz misteriosa do corpo. (RENAULD, 2010: 3)

Dada a perspectiva atual de cuidado em que se fundamenta a Enfermagem, vinculada a uma noção de integralidade, a uma perspectiva holística e humanizada, a oposição entre este modelo de prática e um cenário em que corpo e pessoa encontram-se cindidos aparenta ser uma preocupação para a área, dada a tradição epistemológica em que se forjou a biomedicina e que se pautam, também, às atividades dos enfermeiros (SILVEIRA, GUALDA e SOBRAL, 2003). Nesse sentido, a relação destes profissionais com a dimensão corporal coloca-nos questões, por se constituir como um fazer pautado no cuidado, percebido como integral e holístico e, ao mesmo tempo, fundamentada na biomedicina, uma prática que, como já discutido, enfatiza a dimensão fisiológica e dualista nos processos de cura e que, como vimos, impacta amplamente a forma como esses sujeitos concebem seus corpos e os corpos daqueles que cuidam. Nossa percepção é de que tal dualidade se evidencia nas concepções em torno do que é o corpo no interior dos contextos de cuidado, sendo possível perceber diferentes formas de concebê-lo. Contudo, a Enfermagem parece estar imersa em uma tentativa de superar esta dualidade, ao voltar sua prática para a noção de cuidado. Parece-nos, inclusive, que uma dimensão holística do corpo se torna cada vez mais presente neste âmbito, coexistindo com as concepções características do modelo biomédico.

\section{Considerações finais}

Este trabalho buscou tecer algumas considerações e reflexões acerca de como o corpo é percebido no âmbito da Enfermagem, partindo da bibliografia da área sobre o tema. Como vimos, a Enfermagem possui grande influência do modelo biomédico no que tange a concepção de corpo, já que ela se estruturou em torno de tais princípios. Entretanto, as dimensões psicológica, social, emocional e cultural aparentam ter bastante relevância, principalmente quando a categoria estudada aparece junto à noção de cuidado, reivindicada como prática específica e essencial para a atuação das enfermeiras e enfermeiros. Le Breton (2003) já havia nos mostrado como ao corpo são atribuídos todo um conjunto de sentidos e imaginários, fazendo com que ele se situe dentro de uma estrutura simbólica específica, ressaltando ainda que, embora uma representação possua predominância, ela não se fará unânime, dado o caráter do contexto social em que vivemos. Assim, o que nos propusemos aqui foi pensar essa heterogeneidade dentro do âmbito da saúde, onde se originou a concepção dominante do que é o corpo nas sociedades ocidentais modernas, pensando-a a partir de uma área profissional específica. Como a Enfermagem, uma área do campo da saúde e fundamentada no modelo biomédico, concebe o que é o corpo?

Tal área parece manejar noções próprias e específicas acerca do que é o corpo e a respeito da forma como ele deve ser cuidado. Ao mesmo tempo em que a área da Enfermagem traz consigo uma herança do modelo biomédico que a fundamentou desde os primórdios, ela parece suspender a dicotomia que o sustenta, considerando aspectos por ele desvalorizados. Pautando-se na noção de cuidado, enfermeiras e enfermeiros enfatizam, por diversas vezes, a importância das dimensões emocional, social, espiritual e cultural, focando em um olhar e em uma assistência que enfatize a integralidade do outro.

O que nos parece importante ressaltar aqui é a disputa epistemológica que envolve as áreas que compõem o campo da saúde, principalmente a Enfermagem 
e a Medicina. Este âmbito mostra-se marcado por uma série de hierarquias, discursos e disputas vinculadas ao reconhecimento da importância de práticas próprias de cada ofício. No que concerne mais especificamente a Enfermagem, é possível percebê-la como uma profissão formada de acordo com os princípios da biomedicina e que carrega os impactos desta, mas ao mesmo tempo, um fazer que mobiliza a noção de uma prática específica. Nesse sentido, parece-nos que o cuidado - reivindicado como um fazer que envolve não somente uma dimensão prática, mas uma dimensão subjetiva -, parece ser uma forma de se distanciar do paradigma mecanicista e todas as suas consequências, suspendendo suas dicotomias e situando a atividade das enfermeiras e enfermeiros como um fazer particular, específico e atento aos aspectos humanizados da assistência.

Recebido em 31 de agosto de 2019.

Aprovado em 6 de fevereiro de 2020.

\section{Referências}

BALDUINO, Anice de Fátima Ahmad; MANTOVANI, Maria de Fátima; LACERDA, Maria Ribeiro. O processo de cuidar de enfermagem ao portador de doença crônica cardíaca. Escola Anna Nery Revista de Enfermagem, 13 (2): 342351, 2009.

BONET, Octávio. Saber e sentir: uma etnografia da aprendizagem da biomedicina. Rio de Janeiro: Editora Fiocruz, 2004.

DIAS, Kalina Coeli Costa de Oliveira et al. O cuidado em enfermagem direcionado para a pessoa idosa:revisão integrativa. Revista de Enfermagem UFPE on line, 8 (5): 1337-1346, 2014.

FERNANDES, Carlos Roberto. O corpo mediador do cuidado de enfermagem: uma epistemologia do conceito fundamentada em Wilhelm Dilthey. Tese (Doutorado em Enfermagem), Universidade Federal do Rio de Janeiro, 2016.

FERNANDES, Otília Maria Teixeira; LOPES, Maria dos Anjos Pereira. Corpo, saúde e doença: que representação dos enfermeiros? In: IV Congresso Português de Sociologia, 2000.

FERREIRA, Jaqueline. “O corpo signo”. In: ALVES, P. C.; MINAYO, M. C. S. (Org.). Saúde e doença: um olhar antropológico. Rio de Janeiro: Editora FIOCRUZ, 1994. pp. 101-112.

FONSECA, Rosa Maria Godoy Serpa et al. Gênero e História da Enfermagem. In: OGUISSO, Taka et al. Pesquisa em História da Enfermagem. Barueri: Editora Manole, 2011.

HELMAN, Cecil G. Cultura, saúde e doença. Porto Alegre: Artmed, 2009.

LE BRETON, David. Antropologia do Corpo e Modernidade. 3. Ed. Florianópolis: Vozes, 2013. 
LE BRETON, David. A sociologia do corpo. Petrópolis: Vozes, 2012

LIMA, Renata Campos de; BRÊTAS, José Roberto da Silva. A corporalidade do cliente segundo representações de estudantes de enfermagem. Revista Brasileira de Enfermagem, 59 (6): 727-733, 2006.

NETO, David Lopes; NÓBREGA, Maria Miriam Lima da. Holismo nos modelos teóricos de Enfermagem. Revista Brasileira de Enfermagem, 52 (2): 233-242, 1999.

OGUISSO, Taka. Trajetória Histórica e legal da Enfermagem. Barueri: Manole, 2007.

OLIVEIRA, Francisco J. Arsego de. "Concepções de Doença: o que os serviços de saúde têm a ver com isto?” In: DUARTE, Luiz Fernando; LEAL, Ondina Fachel. Doença, sofrimento e perturbação: perspectivas etnográficas. Rio de Janeiro: Editora FIOCRUZ, 1998. pp. 81-94.

POLAK, Ymiracy Nascimento de Souza. A corporeidade como resgate do humano na enfermagem. Doutorado em Filosofia da Enfermagem - Centro de Ciências da Saúde, Universidade Federal de Santa Catarina, 1996.

RENAUD, Isabel Carmelo Rosa. O Cuidado em Enfermagem. Revista Pensar Enfermagem, 14 (1): 2-8, 2010.

RIZZOTTO, Maria Lúcia Frizon. (Re)vendo a questão da origem da Enfermagem profissional no Brasil: a Escola Anna Néry e o mito da vinculação com a saúde pública. Dissertação (Mestrado em Educação), Universidade Estadual de Campinas, 1995.

ROHDEN, Fabíola. Uma ciência da diferença: sexo e gênero da medicina da mulher. Rio de Janeiro: Editora FIOCRUZ, 2009.

SAILLANT, Francine; GAGNON, Éric. Vers une anthropologie des soins? Anthropologie et Sociétés, 23 (2): 5-14, 1999.

SILVEIRA, Maria de Fátima de Araújo Silveira; Gualda, Dulce Maria Rosa; SOBRAL, Vera R. S. Corpo e enfermagem: (ainda) uma relação tão delicada! Online Brazilian Journal of Nursing, 2 (3) : 3-10, 2003.

SOUZA, Maria de Lourdes et al. O cuidado em enfermagem - uma aproximação teórica. Texto Contexto Enfermagem, 14 (2): 266-270, 2005.

WALDOW, Vera Regina. Cuidar: expressão humanizadora da Enfermagem. Petrópolis: Vozes, 2012. 


\section{Em branco}

ô

ขิ

艺

푿

ลิ

\% ․

을

홍요

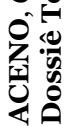

246 